\title{
Ebola lessons guide International Health Regulations review
}

$\mathrm{T}$ he future success of the world's emergency health response system hangs in the balance as the World Health Organization (WHO) announced a review of the International Health Regulations (IHR) this week. The IHR have governed global surveillance and intervention since 2007 and just underwent their most serious trial in the Ebola outbreak in West Africa.

In the current Ebola emergency, "some trust may have been lost," explained Dr. Kumanan Wilson, a senior scientist in the clinical epidemiology program at the Ottawa Hospital Research Institute who has worked as a consultant to the WHO on the IHR. Wilson pointed to a Médecins Sans Frontières (MSF) report that criticized the WHO for dismissing MSF's early reports of Ebola and its spread, as well as failing to provide direction and leadership.

MSF's International President Dr. Joanne Liu, a Canadian physician, said, "It's a failure of political will that prevented the world from responding in the first six months," rather than any problem with funding, expertise or technology. "The location [West Africa] is not a priority in terms of trade or political leverage."

The IHR rely on the cooperation of member nations, agree Wilson and Liu. Wilson said poorer countries need "capacity to identify health risks and assurance that there is a reward to reporting risks." These countries need assistance to cope with outbreaks and protection from negative economic consequences.

A WHO review committee will begin work in August 2015 and report to the World Health Assembly in May 2016, said Dr. Bruce Aylward, WHO's assistant director-general in charge of polio and emergencies, at a press conference in Geneva May 26, as the current assembly wrapped up. The review will look at how effective the IHR were during the Ebola outbreak and how to improve their effectiveness in future

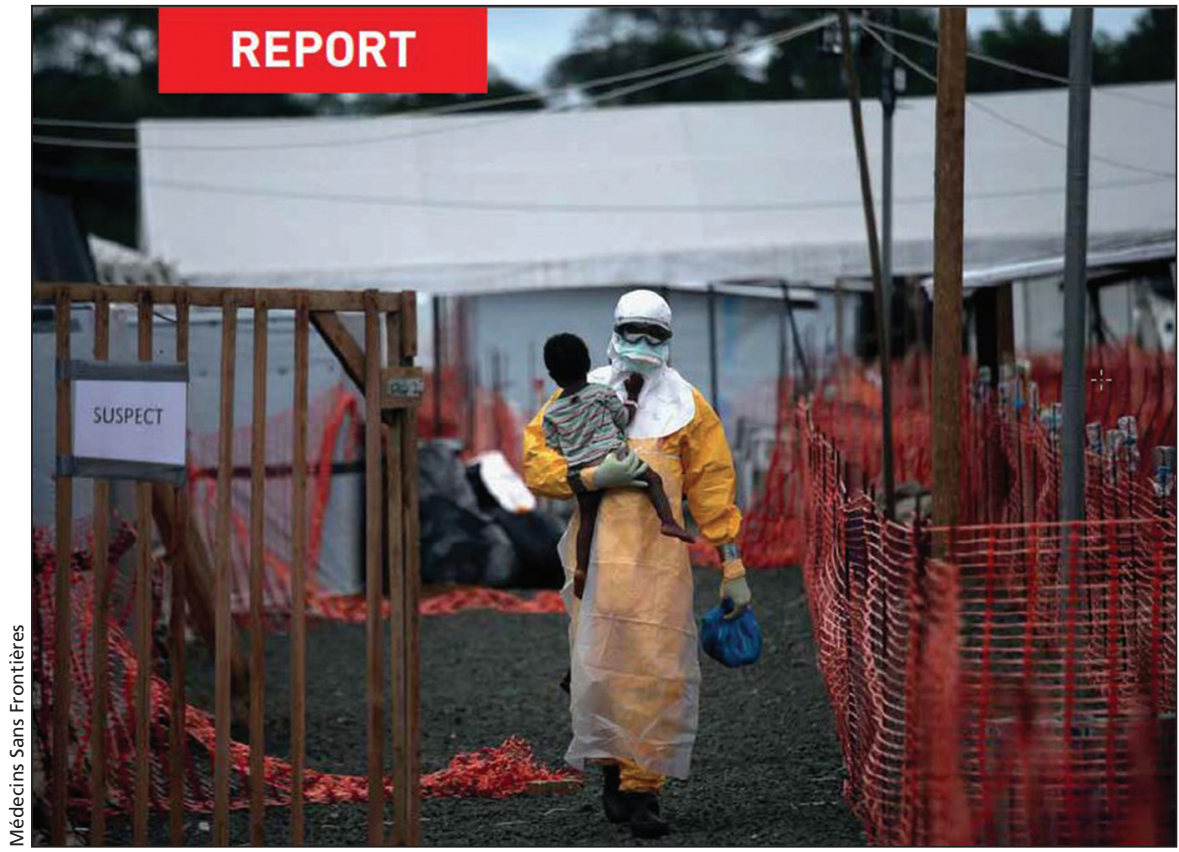

A Médecins Sans Frontières report criticized the WHO for dismissing early reports of Ebola and failing to provide direction and leadership.

emergencies, explained Aylward, a Canadian physician and epidemiologist.

Only 64 of the 196 countries covered by the IHR meet even the basic requirements, according to the WHO. The IHR require countries to conduct surveillance to detect health risks and report them immediately. The deadline for countries to implement the regulations has been extended to 2016 .

Wilson said this requirement can stretch thin resources. "For poorer countries that have on-the-ground issues like HIV, malaria or TB, if you can't conduct the surveillance on the ground level, you won't be able to detect outbreaks."

He said "wealthier countries need to provide support for surveillance in lesser-developed countries." They could do this by supplying expertise to the WHO and training public health professionals in developing countries, he suggested in an article in Policy Options. Doing so "may actually pay off economically for wealthier countries" by preventing costly pandemics. "This needs to be viewed as a win-win." The WHO is suggesting pairing "well-resourced" countries with poorer countries to help them meet their IHR requirements.

Liu believes one of the issues is the long "shopping list" of compliance criteria. She has suggested that the WHO prioritize the criteria to simplify implementation: "Tell countries three things they need to comply with."

The WHO is also reforming its emergency program in light of Ebola, creating a single program for all health emergencies, not only infections, said Aylward. The WHO will also look at how to coordinate a "global health emergency workforce" that includes independent local and partner-country agencies as diverse as youth corps and military personnel. A US\$100-million "contingency fund" for emergency field operations will also be put in place.

Liu and Wilson are guardedly positive about the reforms. Said Liu, "There's a lot of good design on paper; the issue is how it is going to be implemented."

Wilson said, "Those initiatives are great." However, "what is the incentive 
for lower-income countries to even comply with the IHR?" he asked. Governments may fear that reporting an outbreak will result in other countries shutting off trade and travel, with devastating economic consequences. In the Ebola outbreak, the WHO argued that travel restrictions were not appropriate, but
Canada and Australia cancelled travel visas from the affected countries, contrary to the IHR. Wilson said the problem with international agreements like the IHR is that they lack teeth. "There have to be some repercussions to the countries" that violate the regulations.

He said countries have to feel confi- dent that they will get the support they need in a health crisis and that they will not suffer economically. "If those two things don't happen, the IHR is just another document." - Carolyn Brown, Ottawa, Ont.

CMAJ 2015. DOI:10.1503/cmaj.109-5081 